\title{
A direct comparison of rejection by CD8 and CD4 T cells in a transgenic model of allotransplantation
}

\author{
Paige M. Porrett ${ }^{1}$, Major K. Lee IV ${ }^{1}$, Moh Moh Lian ${ }^{1}$, Jing Wang ${ }^{1}$, Andrew J. Caton ${ }^{2}$, \\ Shaoping Deng ${ }^{3}$, James F. Markmann ${ }^{3}$ and Daniel J. Moore ${ }^{1,4}$ \\ ${ }^{1}$ Harrison Department of Surgical Research, Department of Surgery, Hospital of the University of Pennsylvania, \\ Philadelphia, PA 19104, USA \\ ${ }^{2}$ The Wistar Institute, Philadelphia, PA 19104, USA \\ ${ }^{3}$ Division of Surgery, Department of Transplantation, Mass. General Hospital, Boston, MA 02114, USA \\ ${ }^{4}$ Department of Pediatrics, Division of Endocrinology and Diabetes, Vanderbilt Children's Hospital, Nashville, TN 37232, \\ USA
}

Received: 2007.09.12, Accepted: 2008.01.08, Published online first: 2008.05.30

\begin{abstract}
Introduction: The relative contributions of $\mathrm{CD}^{+}$and $\mathrm{CD} 8^{+} \mathrm{T}$ cells to transplant rejection remain unknown. The authors integrated a previous model of CD4-mediated graft rejection with a complementary model of CD8-mediated rejection to directly compare the function of graft-reactive $\mathrm{CD} 4^{+}$and $\mathrm{CD} 8^{+}$lymphocytes in vivo in a model where rejection requires transgenic $\mathrm{T}$ cells. These studies allow direct comparison of CD4 and CD8 T cell responses to the same antigen without the confounding effects of $\mathrm{T}$ cell depletion or homeostatic proliferation.

Materials and Methods: Clone 4 and TS1 mice possess MHC class I- and II-restricted CD8 ${ }^{+}$and $\mathrm{CD}^{+} \mathrm{T}$ cells, respectively, which express transgenic $\mathrm{T}$ cell receptors that recognize the influenza hemagglutinin antigen (HA). We compared the in vivo response of CFSE-labeled, HA-specific transgenic $\mathrm{CD} 8^{+}$and $\mathrm{CD}^{+} \mathrm{T}$ cells after adoptive transfer into syngeneic $\mathrm{BALB} / \mathrm{c}$ mice grafted with HA-expressing skin.

Results: As in the authors' CD4+ model, HA104 skin was consistently rejected by both Clone 4 mice (n=9, MST: 14.2) and by $5 \times 10^{5}$ Clone 4 lymphocytes transferred to naive BALB/c hosts that do not otherwise reject $\mathrm{HA}^{+}$grafts. Rejection correlated with extensive proliferation of either graft-reactive $T$ cell subset in the draining lymph nodes, and antigen-specific $\mathrm{CD}^{+}$and $\mathrm{CD}^{+}$cells acquired effector function and proliferated with similar kinetics.

Conclusions: These data extend the authors' unique transgenic transplantation model to the investigation of CD8 T cell function. The initial results confirm fundamental functional similarity between the CD4 and CD8 T cell subsets and provide insight into the considerable redundancy underlying $\mathrm{T}$ cell mechanisms mediating allograft rejection.
\end{abstract}

Key words: CD4, CD8, proliferation, differentiation, transplantation, rejection.

Abbreviations: CFSE - carboxyfluorescein succinimidyl ester, HA - hemagglutinin antigen, i.p. - intraperitoneal, MST mean survival time, TCR - T cell receptor.

Corresponding author: Daniel J. Moore, Harrison Department of Pediatrics, Vanderbilt Children's Hospital, 2200 Children's Way, 11136 Doctors' Office Tower, Nashville, TN 37232-9170, USA, e-mail: daniel.moore@vanderbilt.edu

\section{INTRODUCTION}

While our understanding of the cellular basis of allograft rejection continues to grow, the relative contributions of $\mathrm{CD}^{+}$and $\mathrm{CD}^{+} \mathrm{T}$ cell subsets to this process remain unclear. Though current evidence suggests that the collaboration of $\mathrm{CD}^{+}$and $\mathrm{CD} 8^{+} \mathrm{T}$ cells maximizes graft rejection $[9,21]$, either population alone can mediate rejection under particular conditions [11-14, 20, 22, 27]. $\mathrm{CD}^{+}$and $\mathrm{CD} 8^{+} \mathrm{T}$ cells also exhibit differential sensitivity to calcineurin inhibitors [3], respond differ- ently to suppression by $\mathrm{CD} 4^{+} \mathrm{CD} 25^{+} \mathrm{T}$ regulatory cells [19], and possess different costimulatory and growth factor requirements [24]. Hence an improved understanding of how these subsets cooperatively respond to alloantigen may allow the development of more comprehensive immunosuppression strategies that minimize graft rejection and systemic toxicity by optimally targeting both effector subsets.

Difficulty elucidating the relative contributions of $\mathrm{CD}^{+}$and $\mathrm{CD} 8^{+} \mathrm{T}$ cells in allograft rejection relates in part to the models used to study their involvement. 
Initial studies utilized depleting anti-CD4 ${ }^{+}$or anti$\mathrm{CD}^{+}$monoclonal antibodies or $\mathrm{CD} 4^{+} / \mathrm{CD}^{+}$knockout mice to determine whether allograft rejection occurs in the absence of either subset [11, 13]. Unfortunately, these approaches have similar limitations in that 1) they do not allow differentiation of donor-reactive $\mathrm{T}$ cells from the more abundant non-reactive host $\mathrm{T}$ cell repertoire, 2) direct comparison of the activation kinetics of $\mathrm{CD}^{+}$and $\mathrm{CD}^{+}$subsets cannot be made, and 3 ) homeostatic proliferation in the immunodeficient host may confound experimental results $[4,26]$. More recently, a transgenic model of allograft rejection suggested fundamental functional similarity between CD4 and CD8 T cells [9]. However, this model was also confounded by rejection in the absence of the transgenic T cells, leaving an open question regarding the function and phenotype of CD4 and CD8 T cells actively involved in mediating graft rejection.

An alternative approach circumventing these concerns is the transfer of graft-specific $\mathrm{CD} 4^{+} / \mathrm{CD} 8^{+} \mathrm{T}$ cells into immunocompetent hosts that do not otherwise reject their allografts, a unique experimental setting that we previously defined for CD4 T cells $[14,15]$. This strategy has several potential advantages. First, the ability of each $\mathrm{T}$ cell subset to independently reject an allograft can be assessed by transferring only $\mathrm{CD}^{+}$or $\mathrm{CD} 8^{+} \mathrm{T}$ cells. Second, the labeling of graft-reactive cells prior to transfer allows them to be visualized and tracked to determine whether $\mathrm{CD} 4^{+}$and $\mathrm{CD} 8^{+}$responders behave similarly in vivo. Third, manipulation of the recipient immune system with depleting antibodies or the use of immunodeficient hosts is not required. Finally, in our model, graft-reactive T cells are absolutely required for graft rejection. To investigate the interplay of $\mathrm{CD}^{+}$and $\mathrm{CD} 8^{+} \mathrm{T}$ cells in graft rejection, we developed a model of transplant rejection based on the transfer of antigen-specific $\mathrm{CD} 8^{+} \mathrm{T}$ cells to immunocompetent hosts which complements our existing $\mathrm{CD}^{+}$ model $[14,15]$. In this study we use this model to directly compare the activation and function of $\mathrm{CD}^{+}$and $\mathrm{CD} 4^{+}$effector cells responding to a common antigen in vivo.

\section{MATERIALS AND METHODS}

Animals

HA104 transgenic mice, developed by Caton et al. [5], contain DNA encoding the full-length influenza virus A PR8 hemagglutinin antigen (HA) polypeptide linked to the SV40 early region promoter-enhancer. Translation of this transgene product results in ubiquitous HA expression on all tissues in HA104 mice. Thy $1.1^{+}$Clone $4 \mathrm{~T}$ cell receptor (TCR) transgenic mice were generously provided by Linda A. Sherman (The Scripps Research Institute, La Jolla, CA). Clone 4 mice possess a high frequency of MHC class I K $\mathrm{K}^{\mathrm{d}}$-restricted $\mathrm{CD} 8^{+} \mathrm{T}$ cells which express a transgenic TCR $(\mathrm{V} \alpha 10$,
Vß8.2) specific for the $\mathrm{HA}_{512-520}$ epitope [18]. TS1 transgenic mice possess a high frequency of $\mathrm{CD}^{+} \mathrm{T}$ cells specific for the immunodominant (Site $1, \mathrm{HA}_{110-120}$ ) epitope of the influenza HA protein in the context of MHC class II I-E ${ }^{d}[14]$. All transgenic mice were bred onto the BALB/c background, and transgene expression in graft donors or recipients was detected by either flow cytometry (Clone 4, TS1) or polymerase chain reaction (HA104). Immunocompetent BALB/c mice $\left(\mathrm{H}-2^{\mathrm{d}}\right)$ were obtained from the Jackson Laboratory (Bar Harbor, $\mathrm{ME})$. All mice were housed and maintained according to the guidelines established by the Institutional Animal Care and Use Committee of the University of Pennsylvania.

\section{Flow cytometric analysis}

Single-cell suspensions were prepared from peripheral lymph nodes and labeled with fluorochrome-conjugated antibodies for flow cytometric examination. The following antibodies were used in the analysis: peridinin chlorophyll protein-conjugated anti-CD8 (clone 53-6.7), allophycocyanin (APC)-conjugated anti-CD4 (clone RM4-5), R-phycoerythrin (PE)-conjugated anti-Thy 1.1 (clone OX-7), PE-conjugated anti-interferon (IFN)- $\gamma$ (B27), and PE-conjugated anti-Vß8.1, 8.2 (clone MR5-2; PharMingen, San Diego, CA). PE-conjugated anti-Perforin (clone eBioOMAK-D) was purchased from eBioscience (San Diego, CA). Thy 1.1 Clone 4 transgenic $\mathrm{T}$ cells could be identified after transfer into BALB/c mice (Thy 1.2) using anti-Thy 1.1 antibody, and the transgenic TCR could be specifically identified after labeling with anti-V $\beta 8.1,8.2$ antibody. The transgenic TS1 TCR was detected using 6.5 biotin (GibcoBRL) and streptavidin-APC (PharMingen, San Diego, CA).

\section{Animal procedures and histological examination}

As described initially by Billingham and Medawar [1], skin was grafted to the lateral thoracic area of anesthetized mice. Graft size, presence of hair, and scabbing were sequentially monitored and recorded. Graft rejection was defined as greater than $75 \%$ graft destruction.

\section{Fluorescent labeling}

Labeling with carboxyfluorescein succinimidyl ester (CFSE) was performed as previously described [16].

\section{$C D 4^{+} T$ cell depletion}

$500 \mu \mathrm{g}$ of anti-CD4 depleting antibody (GK1.5, Bioexpress, West Lebanon, $\mathrm{NH}$ ) was injected intraperitoneally into target mice on day 5 prior to skin grafting. Depletion of the CD4 T cell compartment in both peripheral lymph nodes and the blood was confirmed by flow cytometry prior to skin transplantation. Injections were repeated every 5 days until sacrifice. 


\section{Statistics}

Average duration of graft survival is reported as the mean survival time (MST). Graft survival among groups was compared according to the method of Kaplan and Meier using the log-rank test. Fisher's exact test and Student's $t$-test (2-tailed) were used to compare categorical and continuous variables, respectively, where appropriate. Statistical analysis was performed with SPSS software (version 11.0, Chicago, IL). P values less than 0.05 were considered statistically significant.

\section{RESULTS}

Transgene-positive Clone 4 mice reject HA104

skin grafts in an antigen-specific fashion

Given the high frequency of HA-specific $\mathrm{CD}^{+}$ $\mathrm{T}$ lymphocytes known to circulate in transgene-positive $\left(\mathrm{Tg}^{+}\right)$Clone 4 mice [18], we hypothesized that HA104 skin grafts would be rapidly rejected by $\mathrm{Tg}^{+}$Clone 4 hosts in an antigen-specific fashion. We observed consistent and vigorous rejection of HA104 skin grafts by $\mathrm{Tg}^{+}$Clone 4 mice ( $\mathrm{n}=9$, MST: 14.2 days; Fig. 1). Rejection correlated with a dense mononuclear cellular infiltrate consistent with acute cellular rejection (data not shown). Transgene-negative Clone 4 littermates (Thy $1.1^{+}$) accepted HA104 grafts (Thy $1.2^{+}$) indefinitely, indicating that rejection is dependent on the expression of the transgene-encoded TCR $(n=3$, MST $>100$ days, $p=0.006$ vs. transgene-positive animals; Fig. 1). Additionally, HA-negative BALB/c skin transplanted to $\mathrm{Tg}^{+}$Clone 4 mice was accepted indefinitely $(\mathrm{n}=4$, data not shown). Collectively, these results indicate that both transgenic Clone $4 \mathrm{~T}$ cells and graft expression of HA are required for rejection in this model.
To exclude the possibility that $\mathrm{CD}^{+}{ }^{+} \mathrm{T}$ cells expressing the transgenic TCR in the Clone 4 mouse were also required for allograft rejection in this system, we eliminated $\mathrm{CD}^{+}{ }^{+}$lymphocytes from Clone 4 hosts prior to transplant using the depleting anti-CD4 ${ }^{+}$antibody GK1.5. CD4-depleted hosts remained capable of rejecting $\mathrm{HA}^{+}$skin grafts, indicating that $\mathrm{CD}^{+}$cells are capable of independently mediating rejection in transgenepositive Clone 4 hosts (2/4 reject, MST: 26.5 ). That rejection by depleted animals is somewhat less consistent and occurs with a delayed tempo suggests that $\mathrm{CD} 4^{+} \mathrm{T}$ cells may enhance the response and that this model may allow future exploration of subset cooperativity.

Collectively, these results indicate that $\mathrm{CD} 8+\mathrm{T}$ cells from Clone 4 hosts consistently reject HA104 skin grafts. Rejection is dependent on expression of the trangene-encoded TCR and HA expression in the graft. That CD4-depleted Clone 4 mice remain capable of rejecting skin grafts suggests that $\mathrm{CD} 8^{+} \mathrm{T}$ cells alone are capable of mediating rejection.

\section{Clone $4 \mathrm{Tg}^{+}$mice develop antigen-specific immunological memory}

To confirm that graft rejection by the Clone 4 transgenic mouse mimics cellular rejection in normal nontransgenic hosts, we evaluated whether Clone 4 hosts develop a memory response to $\mathrm{HA}$ antigen. When $\mathrm{Tg}^{+}$ Clone 4 mice that had previously rejected HA104 skin were regrafted with HA104 skin, graft rejection recurred with a significantly accelerated tempo, consistent with an anamnestic response $(n=7$, MST: 8 days, $p=0.008$ vs. naïve Clone 4 hosts). We subsequently demonstrated that this memory response could be transferred into syngeneic BALB/c hosts who do not reject HA104 skin. Following complete rejection of HA104 skin grafts, $5 \times 10^{5}$ lymphocytes from $\mathrm{Tg}^{+}$Clone 4 hosts were isolat-

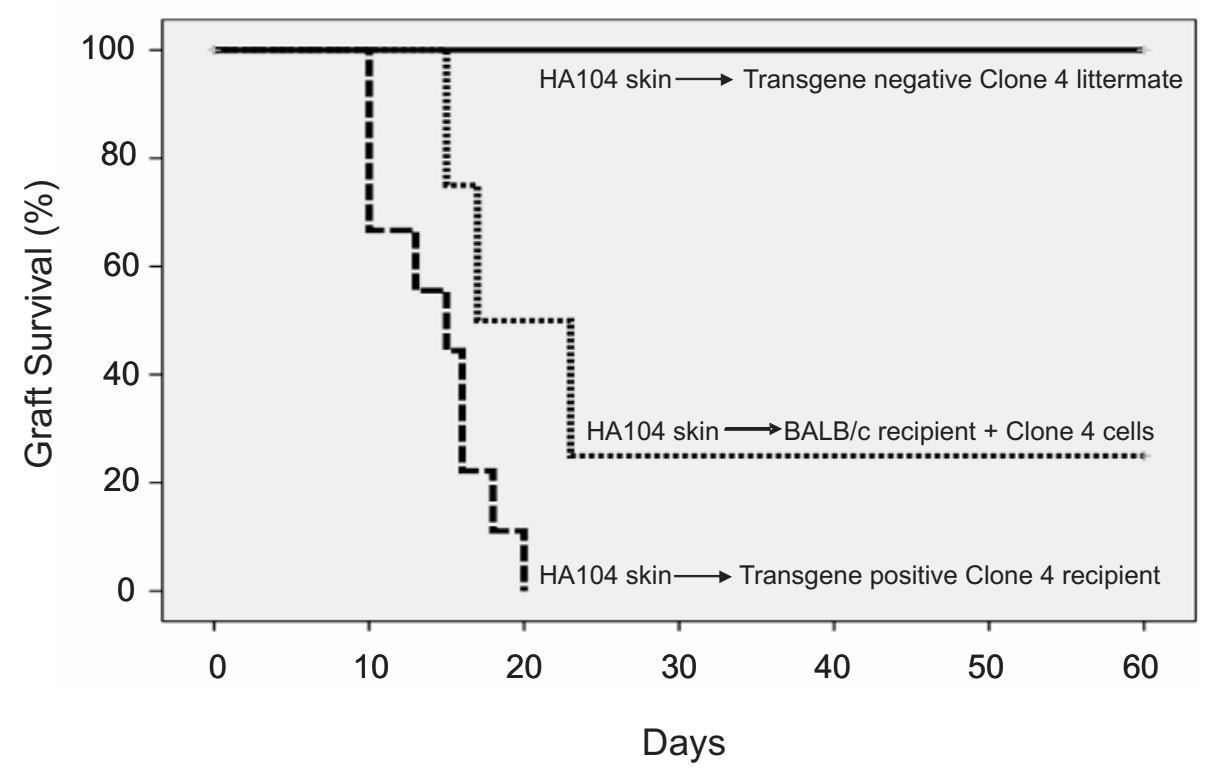

Fig. 1. Rejection of acute HA104 skin transplants by Clone 4 lymphocytes. Clone 4 or BALB/c mice were transplanted with skin grafts harvested from HA104 mice. In the adoptive transfer experiment, lymph nodes were harvested from Clone 4 mice, single cell suspensions were prepared, and $5 \times 10^{5}$ cells were transferred by tail vein injection into $\mathrm{BALB} / \mathrm{c}$ mice bearing HA104 skin grafts. Control mice are transgene-negative Clone 4 littermates grafted with HA104 skin who did not receive adoptively transferred cells. Graft survival was significantly different between transgene-negative littermates and all other groups $(\mathrm{p}<0.002$, log-rank test). These data demonstrate the requirement for HA-reactive transgenic $\mathrm{T}$ cells and HA-expressing skin grafts for rejection. 
ed and injected via tail vein into BALB/c hosts grafted with HA104 skin. These mice promptly rejected the HA104 skin graft with kinetics identical to the directly regrafted $\mathrm{Tg}^{+}$Clone 4 mice ( 3 of 4 host mice rejected, MST: 9 days, $p>0.05$ compared with directly regrafted animals). Taken together, these results indicate that rejection of HA104 skin by Clone 4 hosts duplicates a normal physiological immune response with respect to the development of immunological memory.

\section{Adoptively transferred Clone 4 lymphocytes reject HA104 skin graft}

Having established that Clone 4 hosts consistently reject HA104 skin grafts, we next established an adoptive transfer model in the CD8 transgenic system analogous to that described previously for the CD4 ${ }^{+}$TS1 system $[14,15]$. The adoptive transfer model has a number of advantages. Most notable are that rejection is mediated by a more physiological number of $T$ cells and that labeling graft-reactive cells prior to transfer allows evaluation of their activation in vivo. This model represents a refinement over previous investigations as the transgenic transferred $\mathrm{T}$ cells are required to mediate rejection as non-transgenic animals do not reject $\mathrm{HA}^{+}$skin (Fig. 1).

As we had previously demonstrated that $5 \times 10^{5}$ adoptively transferred $\mathrm{CD} 4^{+} \mathrm{T}$ cells from TS1 hosts consistently reject HA104 skin grafts [14], we determined whether this number of Clone 4 lymphocytes would also mediate rejection. $5 \times 10^{5}$ unfractionated Clone 4 lymphocytes transferred into $\mathrm{BALB} / \mathrm{c}$ recipients grafted one day prior with HA104 skin consistently mediated rejection with a tempo similar to that observed in directly transplanted Clone $4 \mathrm{Tg}^{+}$recipients (3/4 rejected, MST: 18.3 days; Fig. 1). Further investigation suggested that $5 \times 10^{5}$ transferred cells was near optimal for rejection as progressively decreasing the transferred cell number to $7.5 \times 10^{4}$ led to less consistent graft rejection (Fig. 2). We therefore utilized transfers of $5 \times 10^{5}$ cells for further experiments. Flow cytometric analysis demonstrated that Thy $1.1^{+}$Clone 4 lymphocytes constituted on average $0.35 \%$ of peripheral $\mathrm{CD} 8^{+} \mathrm{T}$ cells in $\mathrm{BALB} / \mathrm{c}$ hosts at two weeks following cell transfer (data not shown). Thus, rejection of HA-expressing grafts is maintained when the precursor frequency is decreased to better recapitulate the prevalence of TCRs reactive against minor determinants.

\section{Rejection of HA104 skin grafts correlates with proliferation of Clone $4 \mathrm{CD}^{+} \mathrm{T}$ cells in the draining lymph node}

As mentioned, a principle advantage of the adoptive transfer model is the ability to visualize the function and activation of transferred graft-reactive $\mathrm{T}$ cells. Specifically, labeling lymphocytes prior to transfer with the fluorescein-based dye CFSE allows visualization and quantitative assessment of proliferation [16]. We next

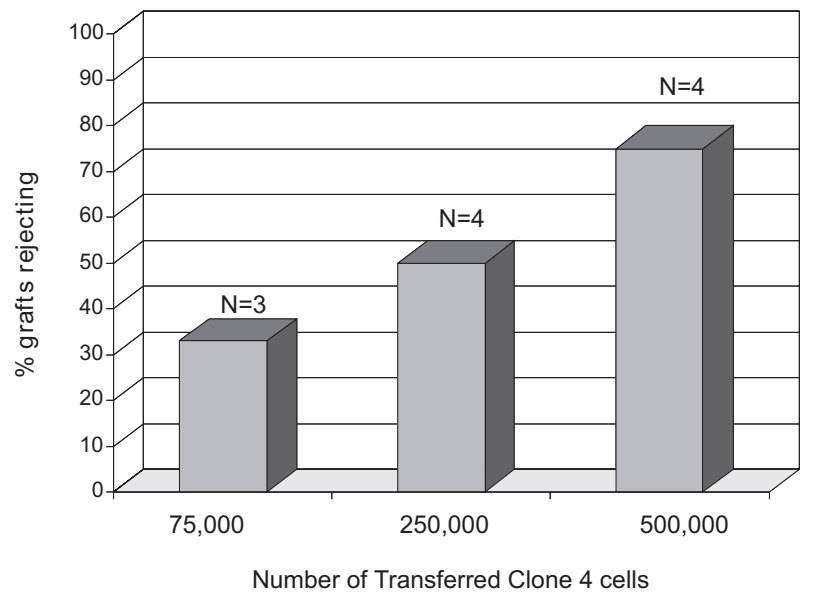

Fig. 2. The frequency of rejection of HA104 skin grafts is proportionately increased by the transfer of Clone 4 lymphocytes. Unfractionated Clone 4 lymph node cells were counted and transferred into immunocompetent BALB/c recipients that were grafted with HA104 skin. Skin-graft survival was monitored daily until rejection. Surviving skin grafts were monitored for two months after cell transfer.

evaluated the in vivo activation of Clone 4-derived $\mathrm{CD}^{+} \mathrm{T}$ cells and compared this with our results using $\mathrm{CD}^{+}{ }^{+} \mathrm{T}$ cells from TCR transgenic TS1 hosts [15].

To analyze the localization and activation of transferred Clone 4 lymphocytes, $5 \times 10^{5}$ unfractionated CFSE-labeled Clone 4 lymphocytes were transferred to BALB/c hosts grafted one-day prior with HA104 skin. Axillary and inguinal lymph nodes ipsilateral and contralateral to the HA104 skin graft were harvested 14 days post-cell transfer and the proliferation of transferred cells was evaluated at each site using flow cytometry. We observed an extensive proliferative response among transferred cells that was largely restricted to the draining lymph node ( $>7$ rounds of division; Fig. 3A). While many cells divided $6+$ times in the draining lymph node, few cells reached $4+$ divisions in contralateral lymph nodes (Fig. 3B). Proliferation was restricted to $\mathrm{CD}^{+} \mathrm{T}$ cells, as the cells expressing low levels of $\mathrm{CD} 8$, a majority of which would be $\mathrm{CD}^{+} \mathrm{T}$ cells, underwent very few rounds of division (Fig. 3A, CD8 $8^{\text {lo }}$ population), providing evidence that the cells proliferating in response to the graft were Clone 4 lymphocytes bearing the transgenic TCR. The observed proliferative response was highly antigen specific, as the frequency of mitotic events amongst HA-specific T cells in the transfer inoculum (best identified by the expression of the transgene-encoded TCR $\beta$ chain V $\beta 8$.2) was significantly higher than that among non-HA-specific cells (avg. number of mitoses/10,000 cells: $5556 \mathrm{~V} \beta 8.2^{+}$vs. 1055 $\mathrm{V} \beta 8.2^{-}, \mathrm{n}=3, \mathrm{p}=0.02$; Figs. $3 \mathrm{C}$ and $\left.\mathrm{D}\right)$. The extent of antigen-specific proliferation of Clone 4 cells ( $>7$ divisions) as well as the restriction of proliferation primarily to the draining lymph node were comparable to the results observed in our previously established TS1 model (Figs. 3E and F). While comparison of Figs. 
Clone 4 Ipsilateral

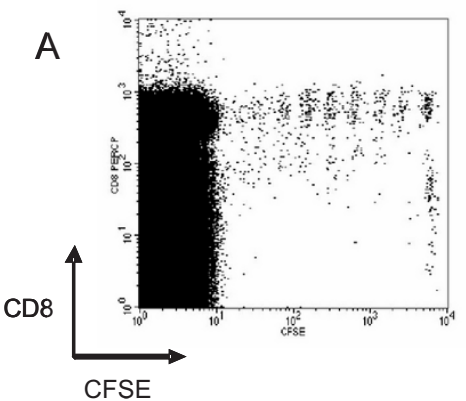

Clone 4 vs BALB

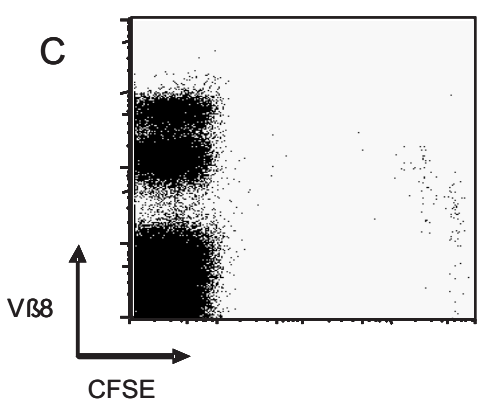

TS1 Ipsilateral

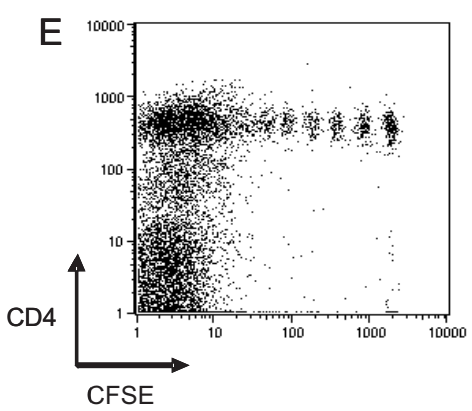

Clone 4 Contralateral

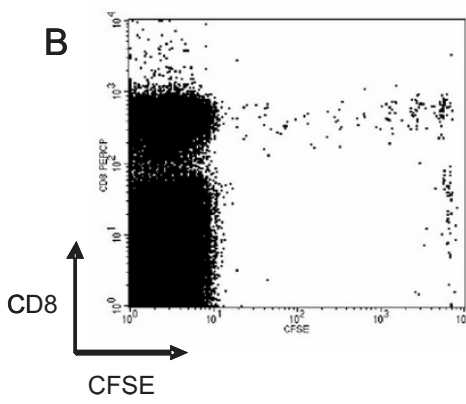

Clone 4 vs HA104

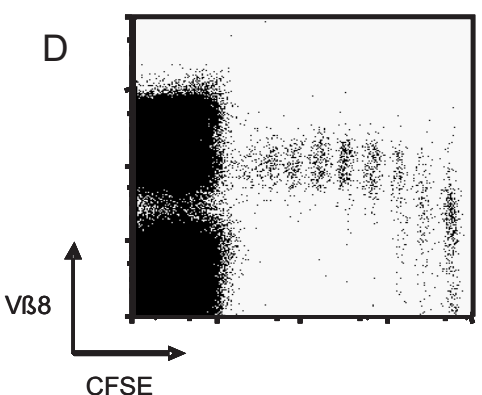

TS1 Contralateral

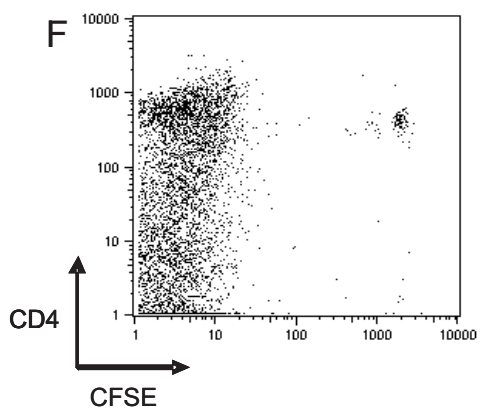

Fig. 3. Clone 4 and TS1 lymphocytes proliferate in the draining lymph node in response to HA104 skin grafts. $5 \times 10^{5}$ unfractionated CFSE-labeled Clone 4 lymph node cells were transferred to BALB/c hosts grafted one day prior with HA104 skin transplants. The proliferative response within the ipsilateral (A) and contralateral (B) inguinal and axillary lymph nodes was assessed 14 days after cell transfer. Proliferation is largely restricted to the $\mathrm{CD} 8^{+}$cells (upper right quadrant); $\mathrm{CD} 8^{\text {lo }}$ (presumptive CD4) cells exhibit little proliferation in this model. Refined analysis examined the proliferative response of $\mathrm{Vb}^{+} \mathrm{T}$ cells which also detects the transgenic TCR. While there was little proliferation of $\mathrm{Vb}^{+}$cells against a BALB/c skin graft $(\mathbf{C})$, these cells demonstrated extensive proliferation driven by HA-expressing skin (D). Proliferation was largely restricted to the Vb8 expressing $\mathrm{T}$ cells as shown demonstrating preferential activation of the transgenic TCR. For comparison, $5 \times 10^{5}$ unfractionated CFSE-labeled TS1 lymph node cells were transferred to BALB/c hosts grafted one day prior with HA104 skin transplants. The proliferative response within the ipsilateral (E) and contralateral (F) inguinal and axillary lymph node was assessed 14 days after cell transfer. As expected, proliferation is restricted almost exclusively to the $\mathrm{CD}^{+}$population; little proliferation is seen among CD $4^{\text {lo }}$ (presumptive CD8) cells in these dot plots. Each experimental condition was replicated on at least four separate occasions.
$3 \mathrm{~B}$ and $\mathrm{F}$ suggests that there may have been slightly more proliferation of Clone $4 \mathrm{CD}^{+}$cells in the contralateral lymph node compared with $\mathrm{TS} 1 \mathrm{CD}^{+}{ }^{+}$cells, this response was highly variable. Whether the proliferation of CD8 T cells is less tightly restricted than that of $\mathrm{CD} 4$ cells would require further investigation.

Collectively, these data indicate that transferred $\mathrm{CD}^{+}$ $\mathrm{T}$ cells from Clone 4 hosts are dynamically comparable to transferred CD4 ${ }^{+} \mathrm{T}$ cells from TS1 hosts [14]. Both populations divided extensively to HA-expressing skin grafts, and proliferation in both instances was highly antigen-specific and largely localized to the draining lymph node.

\section{$\mathrm{CD}^{+}$and $\mathrm{CD} 8^{+} \mathrm{T}$ cells proliferate with similar kinetics early in the rejection response}

The successful development of this antigen-specific model of CD8-mediated rejection provided the unique opportunity to directly compare the proliferative responses of individual $\mathrm{CD}^{+}$and $\mathrm{CD} 8^{+} \mathrm{T}$ cell subsets to a common antigen in vivo. We demonstrated that the proliferation of CD8 and CD4 T cells to HA antigen was comparable at 14 days post-transplant. However, this late time point could represent the peak response, and there may still be differences in the kinetics of activation of CD4 and CD8 T cells post-transplant. We therefore quantitatively examined the kinetics of the proliferative response of each of these $\mathrm{T}$ cell subsets to determine whether antigen-specific proliferation of the CD8 ${ }^{+}$ $\mathrm{T}$ cells mediating graft rejection would parallel that observed in the TS1 CD4 ${ }^{+} \mathrm{T}$ cell subset.

Immunocompetent syngeneic BALB/c host mice grafted with HA104 skin received unfractionated CFSElabeled TS1 or Clone 4 lymphocytes one day after skin transplantation. Recipients were euthanized 5 and 10 days after cell transfer, and the proliferative response at the draining ipsilateral axillary and inguinal, contralateral axillary and inguinal, and distant cervical lymph node sites was assessed by flow cytometry.

Five days after cell transfer, CFSE-labeled lymphocytes from both TS1 and Clone 4 mice could be detected in the cervical, ipsilateral, and contralateral lymph nodes of all recipient $\mathrm{BALB} / \mathrm{c}$ host mice. At this early time point, the CFSE-labeled transgenic $\mathrm{T}$ cells of either 
Day 5
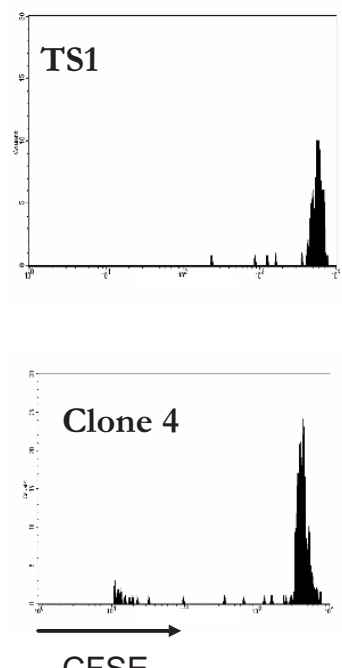

CFSE
Day 10
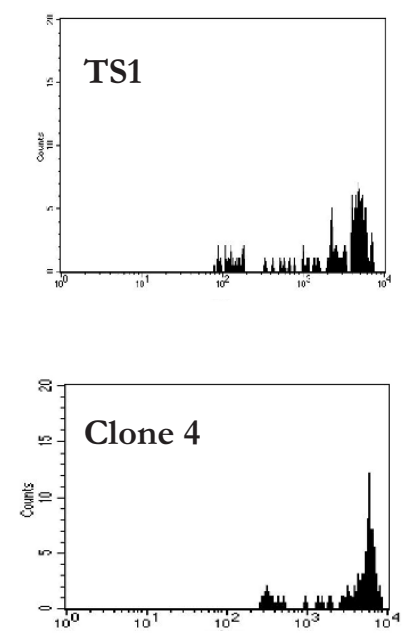
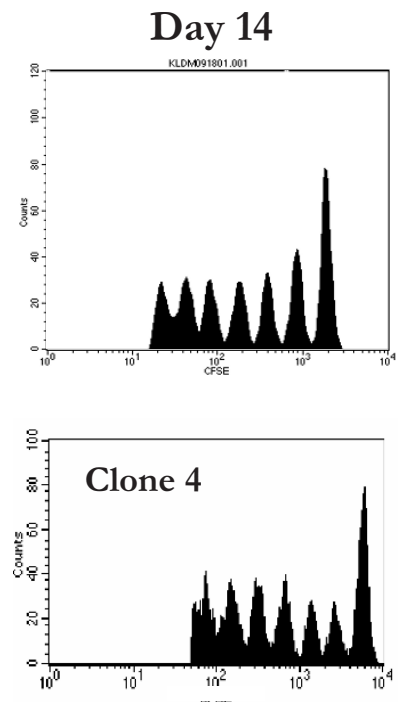

Fig. 4. Kinetics of TS1 and Clone 4 lymphocyte proliferation to HA104 skin grafts. $5 \times 10^{5}$ unfractionated CFSE-labeled TS1 or Clone 4 lymph node cells were transferred to BALB/c hosts grafted one day prior with HA104 skin transplants. The proliferative response within the draining ipsilateral axillary plus inguinal lymph nodes 5 or 10 days after cell transfer is shown. TS1 histograms are gated on CFSE-positive, $\mathrm{CD}^{+}{ }^{+} \mathrm{T}$ cells expressing the transgenic TCR $\left(6.5^{+}\right)$. Clone 4 histograms are gated on CFSE-positive, $\mathrm{CD}^{+}$ $\mathrm{T}$ cells expressing the transgenic TCR $\beta$ chain $\left(\mathrm{V} \beta 8.2^{+}\right)$. The figures shown are representative of three separate experiments.
$\mathrm{T}$ cell subset had undergone very little division (avg. number of mitoses per $10^{4}$ events at ipsilateral lymph nodes: 226 for TS1 $(n=5)$ and 360 for Clone $4(n=3)$, $\mathrm{p}=0.44$; Fig. 4). Ten days after cell transfer, both the TS1 and Clone 4 transgenic $\mathrm{T}$ cell populations demonstrated increased proliferation restricted to the ipsilateral lymph nodes (avg. mitoses per $10^{4}$ events: 769 for TS1 $(n=5)$ and 2399 for Clone $4(n=5)$; Fig. 4). Division for both populations was significantly increased relative to day 5 ( $p=0.05$ for Clone 4, $p<0.0001$ for TS1). There was no significant difference between the proliferation of Clone 4 and TS1 lymphocytes at day 10 post-transplant $(p=0.09)$ although there was a trend toward a more rapid CD8 response (Fig. 4). Therefore, these data indicate that the similar pattern of activation for TS1 and Clone 4 lymph node cells that was initially observed at day 14 post-transplant extends to the early post-transplant period.

\section{$C D 4^{+}$and $C D 8^{+} T$ cells acquire effector function with similar kinetics during the course \\ of antigen-specific proliferation}

Our data suggest that both $\mathrm{CD}^{+}$and $\mathrm{CD} 8^{+} \mathrm{T}$ cells proliferate with similar kinetics in vivo to a common alloantigen. To determine whether these cells also acquire effector function in a similar fashion, we stimulated CFSE-labeled Clone 4 and TS1 lymphocytes in vitro with HA peptide for $72 \mathrm{~h}$ and measured intracellular perforin and IFN- $\gamma$, respectively. Consistent with prior work linking effector function with proliferation $[2,10]$, IFN- $\gamma$ was upregulated after multiple rounds of cellular division within the $\mathrm{CD} 4^{+} \mathrm{T}$ cells. Acquisition of effector function in the $\mathrm{CD}^{+}$compartment mirrored these findings, as perforin protein levels peaked after approximately four rounds of division (Fig. 5). These data suggest that CD4 and CD8 cells not only proliferate with similar kinetics to the same antigen, but also acquire effector function in a similar manner.

\section{DISCUSSION}

Here we present the development of a novel model of CD8-mediated skin-graft rejection which allows a direct comparison of $\mathrm{CD}^{+}$and $\mathrm{CD} 8^{+} \mathrm{T}$ cell responses in vivo to skin grafts bearing a common target antigen. This model represents an important new system for the investigation of CD8 and CD4 T cell function as graft-reactive transgenic $\mathrm{T}$ cells are absolutely required for graft rejection. As cells are transferred into immunocompetent hosts, this model is also protected from the confounding effects of $\mathrm{T}$ cell depletion and homeostatic proliferation. Using CFSE-labeling of the graft-reactive $\mathrm{T}$ cell subsets, we demonstrate that skin-graft rejection correlates with the clonal proliferation of either a $\mathrm{CD} 4^{+}$or a $\mathrm{CD} 8^{+}$antigen-specific $\mathrm{T}$ cell population within the graft's draining lymph nodes, and that both $\mathrm{CD}^{+}$and $\mathrm{CD} 8^{+} \mathrm{T}$ cells proliferate with similar kinetics in response to an allograft. In support of the work of other investigators who have correlated antigen-specific clonal proliferation by $\mathrm{CD}^{+} \mathrm{T}$ cells with subsequent acquisition of $\mathrm{T}$ cell effector function $[2,10]$, we demonstrate that the acquisition of effector function by $\mathrm{CD} 8^{+} \mathrm{T}$ cells is also linked to division cycle.

Our observation that $\mathrm{CD}^{+}$and $\mathrm{CD} 8^{+} \mathrm{T}$ cells both accumulate and proliferate within the graft's draining lymph node is in agreement with findings by Ehst et al. [9], who studied the rejection of ovalbumin (OVA)-expressing skin grafts following the adoptive transfer of OVA-specific MHC class I- and II-restricted transgenic T cells (OT-I and OT-II, respectively) into B6 hosts. However, they were unable to reach a definitive conclusion with respect to graft-reactive cell activity as the transferred transgenic cells were not required for graft rejection. These investigators further demonstrated that co-transfer of both transgenic $\mathrm{T}$ cell subsets resulted in faster graft rejection than transfer of either $\mathrm{T}$ cell subset alone and attributed the accelerated rejection to a dramatic increase in skin-graft infiltration by 
A

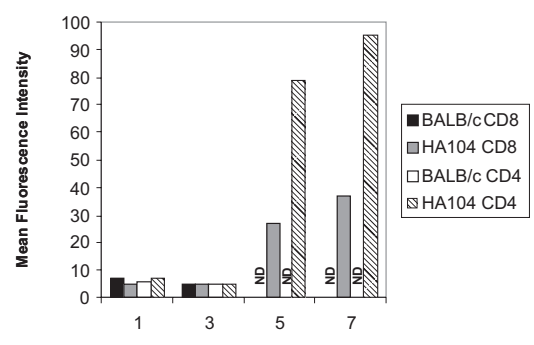

Number of Cell Divisions
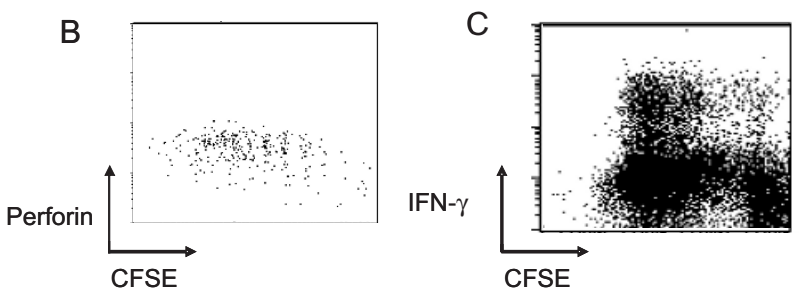

Fig. 5. Clone 4 and TS1 T cells acquire effector function after multiple rounds of antigen-specific proliferation. (A) $5 \times 10^{5}$ CFSE-labeled Clone 4 or TS1 T cells were adoptively transferred into $\mathrm{BALB} / \mathrm{c}$ mice transplanted with HA104 skin or BALB/c syngeneic skin. Fourteen days after transfer, cells were prepared from the draining lymph nodes and restimulated in vitro with HA peptide. For TS1 cells, whole lymph nodes were restimulated with HA peptide. The mean fluorescence intensity of perforin or IFN- $\gamma$ staining was calculated for each round of proliferation from FACS plots; these plots are illustrated in (B) and (C). $1 \times 10^{6}$ CFSE-labeled Clone 4 lymphocytes (B) and $1 \times 10^{6}$ CFSE-labeled TS1 lymphocytes (C) were incubated with HA peptide for $72 \mathrm{~h}$ in vitro. Monensin and PMA/Ionomycin were added for the last $5 \mathrm{~h}$ of culture and intracellular perforin (B) or IFN- $\gamma(\mathbf{C})$ was assessed by FACS on $\mathrm{CD}^{+}$and $\mathrm{CD} 4^{+}$cells, respectively. ND - not detectable. The experimental conditions above were each repeated on at least three occasions.

antigen-specific $\mathrm{CD} 8^{+} \mathrm{T}$ cells in the presence of the $\mathrm{CD}^{+} \mathrm{T}$ cell-subset. Thus, $\mathrm{CD} 4^{+} \mathrm{T}$ cells accelerated rejection in this model by augmenting the generation and/or migration of graft-specific $\mathrm{CD}^{+} \mathrm{T}$ cells. Whether the co-transfer of TS1 and Clone 4 transgenic $\mathrm{T}$ cell populations accelerates skin-graft rejection or modulates the proliferative response of either population is currently under investigation in our laboratory. Our finding that CD4-depleted Clone 4 hosts rejected $\mathrm{HA}^{+}$skin grafts slightly less rapidly and consistently than intact mice supports a role for $\mathrm{CD} 4 / \mathrm{CD} 8$ cooperation in rejection [17]. However, our finding that $\mathrm{CD} 8$ cells had as rapid a response as CD4 cells in isolation suggests that the CD4-CD8 interaction may be more bipartisan than previously appreciated, with CD8 cells also serving to enhance CD4 function [25].

Our findings also have mechanistic implications for the observation that monotherapy with anti-CD4 or anti-CD8 is relatively ineffective in inducing tolerance to skin allografts [6]. As CD4 and CD8 T cells demonstrate contemporaneous activation in this transplant setting, inhibition of one subset may have only limited effect on the other. In contrast, in other tissue allograft settings where anti-CD4 is more effective [7], there may be a delay in CD8 kinetics and CD4 dependency. This hypothesis can be definitively tested with this new model system and is under investigation. These studies may define the optimal targets of and timing for immunotherapy in transplantation settings based on kinetic data. Moreover, this model system may allow us to more effectively distinguish the participation of these cellular subsets in a variety of transplant settings. As we have already established HA-based models of transplant rejection in skin, heart, and liver systems, this model could be expanded to those settings $[8,14,23]$. Whether cellular grafts such as islets will also be successfully explored with these methods will require future testing and refinement.

In conclusion, through the integration of two individual models of antigen-specific CD4 and CD8-mediated graft rejection, we demonstrate remarkable similarity in the cellular mechanisms utilized by $\mathrm{CD}^{+}$and $\mathrm{CD} 8^{+} \mathrm{T}$ cells to acquire effector function and mediate antigen-specific graft rejection. Taken together, these data indicate considerable redundancy in the immune system's ability to mediate graft rejection and suggest that pharmacological therapy which may suppress either but not both of these $\mathrm{T}$ cell subsets may ultimately fail. Future immunotherapy designed to promote allograft survival should therefore target both $\mathrm{T}$ cell subsets simultaneously in order to maximize transplantation success.

Acknowledgment: Financial support for this work was provided by a grant from Ethicon administered through the Society of University Surgeons and R01-AI48820.

\section{REFERENCES}

1. Billingham R. and Medawar P. (1951): The technique of free skin grafting in mammals. J. Exp. Biol., 28, 385.

2. Bird J. J., Brown D. R., Mullen A. C., Moskowitz N. H., Mohowald M. A., Sider J. R., Gajewski T. F., Wang C. R. and Reiner S. L. (1998): Helper T cell differentiation is controlled by the cell cycle. Immunity, 9, 229-237.

3. Bishop D. K. and Li W. (1992): Cyclosporin A and FK506 mediate differential effects on $\mathrm{T}$ cell activation in vivo. J. Immunol., 148, 1049-1054.

4. Bueno V. and Pestana J. O. (2002): The role of $\mathrm{CD}^{+}$ T cells during allograft rejection. Braz. J. Med. Biol. Res., 35, 1247-1258.

5. Caton A. J., Schwartzentruber J. R., Kuhl A. L., Carding S. R. and Stark S. E. (1996): Activation and negative selection of functionally distinct subsets of antibody-secreting cells by influenza hemagglutinin as a viral and neo-self antigen. J. Exp. Med., 183, 13-26.

6. Cobbold S. P., Martin G. and Waldmann H. (1990): The induction of skin graft tolerance in major histocompatibility-mismatched or primed recipients: primed $\mathrm{T}$ cells can be tolerized in the periphery with anti-CD4 and anti-CD8 antibodies. Eur. J. Immunol., 20, 2747-2755.

7. Darby C. R., Morris P. J. and Wood K. J. (1992): Evidence that long-term cardiac allograft survival induced by antiCD4 monoclonal antibody does not require depletion of CD4+ T cells. Transplantation, 54, 483-490. 
8. Deng S., Moore D. J., Huang X., Mohiuddin M., Lee M. K. IV, Velidedeoglu E., Lian M. M., Chiaccio M., Sonawane S., Orlin A., Wang J., Chen H., Caton A., Zhong R. and Markmann J. F. (2006): Antibody-induced transplantation tolerance that is dependent on thymus-derived regulatory T cells. J. Immunol., 176, 2799-2807.

9. Ehst B. D., Ingulli E. and Jenkins M. (2003): Development of a novel transgenic mouse for the study of interactions between CD4 and CD8 T cells during graft rejection. Am. J. Transplant., 3, 1355-1362.

10. Gudmundsdottir H., Wells A. D. and Turka L. A. (1999): Dynamics and requirements of $\mathrm{T}$ cell clonal expansion in vivo at the single-cell level: effector function is linked to proliferative capacity. J. Immunol., 162, 5212-5223.

11. Haskova Z., Usiu N., Pepose J., Ferguson T. A. and Stuart P. M. (2000): CD4+ T cells are critical for corneal, but not skin, allograft rejection. Transplantation, 69, 483-487.

12. Jones N. D., Turvey S. E., Van Maurik A., Hara M., Kingsley C. I., Smith C. H., Mellor A. L., Morris P. J. and Wood K. J. (2001): Differential susceptibility of heart, skin, and islet allografts to T-cell mediated rejection. J. Immunol., 166, 2824-2830.

13. Krieger N. R., Yin D. and Fathman C. G. (1996): CD4+ but not CD8+ cells are essential for allorejection. J. Exp. Med., 184, 2013-2018.

14. Lee M. K. 4th, Huang X., Jarrett B. P., Moore D. J., Desai N. M., Moh Lian M., Markmann J. W., Deng S., Frank A., Singer A., Velidedeoglu E., Caton A. J. and Markmann A. J. (2003): Vulnerability of allografts to rejection by MHC Class II-restricted T-cell receptor transgenic mice. Transplantation, 75, 1415-1422.

15. Lee M. K. 4th, Moore D. J., Jarrett B. P., Lian M. M., Deng S., Huang X., Markmann J. W., Chiaccio M., Barker C. F., Caton A. J. and Markmann J. F. (2004): Promotion of allograft survival by $\mathrm{CD} 4+\mathrm{CD} 25+$ regulatory $\mathrm{T}$ cells: evidence for in vivo inhibition of effector cell proliferation. J. Immunol., 172, 6539-6544.

16. Lyons A. and Parish C. (1990): Determination of lymphocyte division by flow cytometry. J. Immunol. Methods, 171, 131-137.

17. Mintern J. D., Davey G. M., Belz G. T., Carbone F. R. and Heath W. R. (2002): Cutting edge: precursor frequency affects the helper dependence of cytotoxic $\mathrm{T}$ cells. J. Immunol., 168, 977-980.
18. Morgan D. J., Liblau R., Scott B., Fleck S., McDevitt H. O., Sarvetnick N., Lo D. and Sherman L. A. (1996): CD8+ $\mathrm{T}$ cell-mediated spontaneous diabetes in neonatal mice. J. Immunol., 157, 978-983.

19. Piccirillo C. A. and Shevach E. M. (2001): Cutting edge: control of $\mathrm{CD} 8+\mathrm{T}$ cell activation by $\mathrm{CD} 4+\mathrm{CD} 25+$ immunoregulatory cells. J. Immunol., 167, 1137-1140.

20. Rosenberg A. S., Munitz T. I., Maniero T. G. and Singer A. S. (1991): Cellular basis of skin allograft rejection across a class I major histocompatibility barrier in mice depleted of CD8+ T cells in vivo. J. Exp. Med., 173, 1463-1471.

21. Rosenberg A. and Singer A. (1992): Cellular basis of skin allograft rejection: an in vivo model of immune-mediated tissue destruction. Annu. Rev. Immunol., 10, 333-358.

22. Valujskikh A., Matesic D. and Heeger P. S. (1999): Characterization and manipulation of $\mathrm{T}$ cell immunity to skin grafts expressing a transgenic minor antigen. Transplantation, 68, 1029-1036.

23. Velidedeoglu E., Jarrett B., Lee K., Moore D., Huang X., Deng S., Lian M. M., Caton A., and Markmann J. F. (2002): Transgenic T cell persist in an adoptive transfer model of mouse liver transplantation tolerance. Transplant. Proc., 34, 3342-3344.

24. Vu M. D., Amanullah F., Li Y., Demirci G., Sayegh M. H. and Li X. C. (2004): Different costimulatory and growth factor requirements for CD4+ and CD8+ T cell-mediated rejection. J. Immunol., 173, 214-221.

25. Wang B., Norbury C. C., Greenwood R., Bennink J. R., Yewdell J. W. and Frelinger J. A. (2001): Multiple paths for activation of naïve $\mathrm{CD} 8^{+} \mathrm{T}$ cells: CD4-independent help. J. Immunol., 167, 1283-1289.

26. Wu Z., Bensinger S. J., Zhang J., Chen C., Yuan X., Huang X., Markmann J. F., Kassaee A., Rosengard B. R., Hancock W. W., Sayegh M. H. and Turka L. A. (2004): Homeostatic proliferation is a barrier to transplantation tolerance. Nat. Med., 10, 87-92.

27. Yang J., Jaramillo A., Liu W., Olack B., Yoshimura Y., Joyce S., Kaleem Z. and Mohanakumar T. (2003): Chronic rejection of murine cardiac allografts discordant at the H13 minor histocompatibility antigen correlates with the generation of the H13-specific CD8+ cytotoxic T cells. Transplantation, 76, 84-91. 